\section{O RACIONALISMO CARTESIANO POSTO EM QUESTÃO}

Carlos Eduardo Pereira Oliveira*

Resumo: No cartesianismo contemporâneo, devido à retomada da teoria da livre criação das verdades eternas, alguns intérpretes trazem ao debate internacional um interessante viés interpretativo do pensamento de Descartes. Segundo eles, ao apresentar a indiferença da vontade como atributo de Deus, Descartes instaura uma concepção totalmente perigosa, da qual derivam a incompatibilidade entre a indiferença divina e o sistema cartesiano, deflagrando, enfim, um irracionalismo radical.

Palavras-chave: Descartes. Liberdade. Indiferença Divina. Racionalismo Irracionalismo.

\section{Considerações iniciais}

As Cartas de Descartes, as Quintas e Sextas Respostas e as Conversações com Burman tornaram pública uma polêmica tese acerca da vontade divina. Nessas obras, é atribuído à vontade de Deus o atributo da indiferença, considerado, contudo, pela Quarta Meditação, uma imperfeição da vontade humana. Nada mais instigante e intrigante do que essa posição, que, após alguns séculos de abandono, é novamente trazida para o centro das discussões no cartesianismo.

Como outrora, à época de Descartes, também agora a tese em questão, por envolver uma radicalidade profunda, é acusada de trazer risco ao sistema racionalista por ele implantado. Estudiosos observam

* Doutorando do Departamento de Filosofia da Universidade de São Paulo.

Texto inicialmente apresentado nas Jornadas Recepção pela Contemporaneidade do Pensamento do

Século XVII, promovidas pelo Grupo de Estudos Espinosanos. que essa tese poderia tornar problemático este sistema, o qual, tal como nos foi legado pela tradição moderna, parece incompatível com um Deus indiferente.

Antes de analisarmos as questões referentes à indiferença, julgo importante considerarmos inicialmente o seguinte:

a) O termo racionalismo alude a diferentes posições filosóficas. Significando, em primeiro lugar, o primado da razão em relação ao sentimento e à vontade, recebe o nome de intelectualismo, pressupondo uma hierarquia de valores entre as faculdades psíquicas. Em segundo lugar, racionalismo pode ser entendido como uma posição segundo a qual somente a razão é capaz de propiciar o conhecimento adequado e verdadeiro do real. Por último, pode significar uma posição que considera a razão a essência do real.

b) Ao racionalismo de Descartes é fundamentalmente necessária uma garantia transcendente, a fim de que não se instaure no interior do seu sistema a dissociação entre a racionalidade humana e a estrutura última da realidade. Todavia, se de um lado Deus é imprescindível à sustentação deste racionalismo, de outro a concepção segundo a qual à ideia de Deus convém o atributo da indiferença pode transformar Descartes num autor irracionalista, destruindo em definitivo o sistema por ele construído. Isto porque, como veremos adiante, a indiferença expressa que a ação divina não é motivada por razões de verdade nem de finalidade à maneira da ação humana, dando margem a uma cisão entre aquilo que a razão acredita corresponder à realidade e aquilo que é efetivamente a realidade. Ora, se de um lado é impossível retirar Deus da discussão, posto sua existência ser necessária ao sistema como um todo, por outro, considerando que o atributo da indiferença constitui a natureza ou essência divina, o racionalismo claudica. Dessa maneira, assim como somos impedidos de admitir Deus sem a indiferença para preservar o racionalismo, igualmente 
o somos de sustentar o racionalismo fundamentado na existência de um Deus absolutamente indiferente, a menos que seja possível compatibilizar a indiferença divina com as exigências de um sistema racionalista.

\section{A indiferença divina}

A noção de indiferença aparece na Quarta Meditação quando da investigação da vontade humana. A indiferença humana possui dois sentidos: negativamente, compreende um defeito no entendimento, sendo o mais baixo grau de liberdade; positivamente, significa o poder de escolher entre contrários; poder fazer ou não fazer algo.

As Cartas de 1630-1649, por sua vez, precisamente aquelas onde é apresentada a teoria da livre criação das verdades eternas, defendem a vontade divina como absolutamente indiferente e, conforme atestam as Sextas Respostas, "uma inteira indiferença em Deus é uma prova muito grande de sua onipotência" (Descartes 1, AT IX, p. 233). Isso nos induz a supor que se trata da mesma indiferença aplicável à vontade divina e à humana ou ainda, que devido ao aspecto negativo, que pode envolver a indiferença da vontade humana, Descartes consideraria apenas o aspecto positivo, ou seja, o livre-arbítrio, aplicando-o a Deus e ao homem.

Entretanto, uma análise mais acurada afasta tal suposição. Com efeito, o aspecto negativo da indiferença é facilmente excluído da vontade divina, por se tratar de um defeito ou imperfeição da vontade. Considerando o aspecto positivo da indiferença da vontade humana, a indiferença divina suprime definitivamente o livre-arbítrio.

Com efeito, Descartes, ao expor a simplicidade divina, afirma que esta exige a absoluta unidade entre as faculdades, isto é, que em Deus entendimento, vontade e ação são uma e a mesma coisa. Assim sendo, não há qualquer possibilidade de distinguir Nele as faculdades nem de se manter qualquer precedência do intelecto à vontade ${ }^{1}$. É assim que a indiferença divina, suprimindo o livre-arbítrio do interior da vontade divina, descarta qualquer possibilidade de identificação desta à indiferença da vontade humana ${ }^{2}$.

Ademais, a indiferença é requerida como prova cabal da onipotência divina:

"Para a dificuldade de conceber como foi livre e indiferente a Deus fazer com que não fosse verdade que os três ângulos de um triângulo fossem iguais a dois retos, ou geralmente que os contraditórios não podem ser conjuntamente, podemos facilmente suprimi-la considerando que a potência divina não pode ter nenhum limite" (Descartes 1, AT IV, pp. 118-119).

De acordo com a passagem, a verdadeira noção de onipotência exige a indiferença. A ação divina totalmente arbitrária, e livre, é também onipotente, isto é, expressa o poder absoluto de estabelecer como verdade o que para o intelecto finito é contraditório ou impossível. A razão disso encontra-se nas Sextas Respostas, completando, finalmente, o significado da indiferença divina:

“... não há ordem, nem lei, nem razão de bondade e de verdade que não dependa dele; de outra maneira, [...] ele não teria sido totalmente indiferente a criar as coisas que ele criou" (Descartes 1, AT IX, p. 235)․․

A indiferença requer o entendimento de que a ação divina, em considerando corretamente a ideia de Deus, por nada pode ser constrangida, 
precedida ou determinada. Trata-se de uma vontade totalmente arbitrária que não age orientada por princípios lógicos, ou mais precisamente, em razão de qualquer inteligibilidade, e tampouco em razão de qualquer finalidade. Essa vontade não é motivada por qualquer consideração previamente estabelecida pelo intelecto divino ou por algo externo a Deus; repudia toda espécie de exigência, interna ou externa (do seu intelecto ou da essência da coisa, respectivamente), ou toda espécie de ordem metafísica, lógica ou moral que se imponha à ação criadora:

"Por exemplo, não é por ter visto que era melhor que o mundo fosse criado no tempo que desde a eternidade, que ele quis criá-lo no tempo; e ele não quis que os três ângulos de um triângulo fossem iguais a dois retos, porque ele conheceu que isto não se podia fazer de outra maneira, etc." (Descartes 1, AT IX, p. 233).

É a identidade entre intelecto e vontade em Deus que conduz Descartes a assumir a liberdade divina como absolutamente indiferente (Cf. H. Frankfurt, 5, p. 41). O que nos leva, consequentemente, a perguntar pelo impacto da posição cartesiana, segundo a qual Deus não age motivado por consideração prévia de qualquer ordem: como fica a veracidade divina, se não há razão de verdade? Pode algo ser verdadeiro para Deus sem sê-lo para a coisa pensante? E a situação da racionalidade humana e do próprio racionalismo ante um Deus cujo poder, liberdade e ação são absolutamente independentes das leis às quais a razão humana sempre esteve segura de que toda a realidade obedece e está adequada?

Tais questionamentos deflagrarão uma interpretação do pensamento cartesiano essencialmente irracionalista e, consequentemente, um novo matiz interpretativo da necessidade, que explicita de modo incisivo o enredamento da razão - para usar uma terminologia cara à modernidade.

\section{Possibilismo cartesiano e enredamento da razão}

O possibilismo é uma interpretação da concepção de Descartes acerca da liberdade divina como absoluta indiferença.

Nas Cartas, todos os exemplos dados como provas da indiferença divina são mostrados em desacordo com os princípios lógicos da razão, isto é, tornando-se possível e verdadeiro àquilo que a razão repudia como absurdo e falso. A indiferença divina se mostra totalmente alheia a considerações valorativas (em razão do bem) ou racionais (em razão da verdade) e inteiramente arbitrária. Se Deus poderia tornar possível o impossível, por exemplo, a soma de dois e dois diferente de quatro, uma circunferência de raios desiguais, um mundo onde o contraditório fosse a regra, porque sua liberdade é indiferente; e se Ele não age em razão de qualquer inteligibilidade nem de finalidade, então tudo leva a crer que a essência do real, ao contrário do que apregoa o racionalismo, não é racional, isto é, não existe nenhuma exigência de inteligibilidade nem de necessidade para que o mundo seja regulado por leis necessárias inerentes ao entendimento humano. Configura-se, portanto, um universo onde tudo é possível ou onde nada é necessário.

Atrelada à onipotência, a indiferença da liberdade divina é concebida por Descartes como o poder de instituir como verdade o que para nós é absurdo. Isso significa que as consideradas realidades necessárias poderiam ter sido falsas e que sua necessidade é contingente. Depois, a carta de 2 de maio de 1644 afirma que nosso espírito finito e criado, por natureza, só pode conceber as coisas possíveis, isto é, tudo o que esteja de acordo com o princípio de inteligibilidade, não sendo capaz de conceber como verdadeiras as coisas que para ele são impossíveis (Descartes 1, AT IV, p. 118). Partindo desta passagem, pode-se argumentar que se algo era possível a Deus, e sendo a vontade divina indiferente, nada nos garante que 
ele não o tenha feito:

"Digo somente que ele me deu um espírito de tal natureza que eu não poderia conceber uma montanha sem vale, ou que o agregado de um e dois não some três, etc. E digo somente que tais coisas implicam contradição em minha concepção" (Descartes 1, AT V, p. 224).

Já neste trecho é afirmado que a única razão para nos ser impossível conceber a verdade das proposições contraditórias se deve a uma característica contingente da razão humana, pois somente ela está inserida no âmbito do logicamente necessário (Cf. Frankfurt 5, p. 44). Certamente, se fôssemos dotados por Deus de outro entendimento, poderíamos compreender a verdade do que consideramos contraditório. Explica Frankfurt que "Deus poderia nos ter dado mentes diferentes. Se assim o fizesse, algumas proposições inconcebíveis seriam concebíveis e outras concebíveis inconcebíveis" (H. Frankfurt, 5, p. 45).

Uma vez que é nossa mente que não pode conceber a verdade das proposições contraditórias, somos naturalmente levados a afirmar que todos os princípios que para nós regem o real são exclusivamente válidos para o entendimento humano, não gozando de validade para as coisas exteriores a ele. Desta maneira, não podemos presumir que o que a mente humana determina como logicamente necessário coincida com as condições últimas da realidade, ou seja, que o que é verdade para o intelecto finito corresponda à natureza das coisas. Com efeito, a necessidade que a razão descobre pertence somente à sua natureza contingente, assegura Frankfurt.

Desponta, portanto, um novo matiz cartesiano acerca da necessidade, o qual the confere um valor puramente epistêmico, abrindo, por conseguinte, um possível abismo entre os juízos racionais, ou seja, aqueles que obedecem à necessidade de não-contradição, e a realidade extramental. Disso emerge a possibilidade de um radical desacordo entre o conhecimento necessário e o conhecimento verdadeiro, de forma que a razão deve conformar-se em saber que o que ela conhece segue apenas as leis que lhe são inerentes, não podendo ter certeza de que o seu conhecimento corresponda à realidade.

As análises de Frankfurt veem nitidamente em Descartes se oporem racionalidade e verdade absoluta. Isso pode ser confirmado ainda levandose em conta as ideias claras e distintas. Com efeito, a carta a Regius, de 24 de maio de 1640, faz uma ressalva quanto ao poder que a percepção clara e distinta exerce sobre a vontade: "nossa mente é de tal natureza que não pode negar o assentimento ao que entende claramente" (Descartes 1, AT III, p. 64). A vontade é determinada pela percepção clara e distinta, de modo que o sujeito fica impossibilitado de recusar o assentimento. Dessa maneira, Descartes estaria mostrando que a necessidade que julgamos encontrar nas coisas se deve à experiência de não se poder recusar o assentimento a estas ideias. Devido a essa experiência, construímos teorias onde o necessário, o impossível, o concebível e o inconcebível para nós são tomados como verdades acerca da realidade em si. O mundo pode ser irracional, diz Frankfurt, mas nosso intelecto é incapaz de concebê-lo assim (Cf. Frankfurt 5, p. 54).

Sob essa perspectiva, a obra de Descartes, ao contrário do que sempre se pensou, estabelece as necessidades e os limites da própria razão; estabelece aquilo de que para nós é impossível duvidar. Para citar um exemplo: se recorrermos, nas Meditações, à demonstração da veracidade divina, que refuta a hipótese do Deus enganador, notaremos que se trata tão-somente de uma demonstração racional, isto é, coerente com os princípios inatos à razão humana, não possuindo qualquer estatuto superior de verdade absoluta. Explica Frankfurt: 
“A prova de que Deus não é enganador, enquanto demonstração racional, estabelece apenas que sua conclusão é requerida pelos princípios da razão humana, demonstra que um Deus enganador é logicamente incoerente" (Frankfurt 5, p. 52).

É assim que as Meditações exploram os limites e as necessidades da própria razão, servindo apenas para determinar o que é racional admitirmos, isto é, o que seria irracional pôr em dúvida, não o que é verdade para Deus ou para os anjos. Não parece muito estranho que a razão fique satisfeita ante o fato de não poder conhecer senão a si própria?

Sob essa ótica, portanto, a tese da indiferença divina acarreta profundos problemas ao racionalismo cartesiano. A razão já não pode ter segurança nem certeza quanto à validade e legitimidade do seu conhecimento e do acordo necessário entre ela e a realidade. O Deus alheio à razão de verdade, de bondade e de finalidade põe sob suspeita a certeza e o reconhecimento racional do próprio Deus como fundamento último da eficácia da razão e, em última análise, a veracidade divina.

Se as coisas ocorrem realmente desse modo, então o racionalismo sob o nome de intelectualismo, enquanto o primado da razão em relação ao sentimento e à vontade, ou o racionalismo entendido como uma posição segundo a qual somente a razão é capaz de propiciar o conhecimento adequado e verdadeiro do real ou como uma posição que considera a razão a essência do real parecem completamente destruídos pela tese da indiferença divina. Autores há, todavia, que, levando em consideração esta mesma tese, esforçam-se por demonstrar a compatibilidade entre a indiferença divina e o sistema racionalista cartesiano ${ }^{4}$.

\section{Indiferença divina e racionalismo cartesiano: o desafio da compatibilidade}

De acordo com nossas investigações, a instauração da compatibilidade entre indiferença divina e racionalismo cartesiano passa necessariamente pela análise de alguns elementos do pensamento de Descartes, que não foram devidamente notados, parece, pelos adversários da interpretação irracionalista. Sendo assim, o desafio da compatibilidade poderá ser melhor enfrentado mediante cuidadosa observação do conceito de criação, desenvolvido na teoria da criação das verdades eternas, na qual, aliás, Descartes elabora a indiferença divina; da exigência inerente ao conceito de onipotência divina e, finalmente, do conceito de incompreensibilidade divina.

\section{A noção de criação em Descartes}

Todas as análises filosóficas do surgimento e do desenvolvimento do conceito de criação na tradição filosófica e teológica mostram seu aparecimento no seio do cristianismo. As vertentes mais ortodoxas de ambas as tradições sempre conceberam a criação como produção dos seres finitos, criados mediante uma causalidade eficiente, ou seja, por ação da vontade de Deus, que escolhe o que será criado. Dessa forma, toda a criação é contingente: poderá ou não existir, ou ainda existe, mas deixará de existir. Nessa concepção reside um pressuposto, a saber, que a realidade decorrente da ação da vontade divina é marcada radicalmente pela contingência ou finitude. As realidades eternas, por sua vez, eram desvinculadas da ação da vontade divina, sendo, portanto, consideradas incriadas. Havia uma relação necessária entre vontade divina, criação e 
existência finita. Dessa maneira, a vontade divina só poderia produzir a realidade contingente.

Como nos anos de 1630-1649 Descartes afirmou a criação das verdades eternas, ou seja, das realidades imutáveis e necessárias, muitos cartesianos acreditam que ele entende criação como produção da realidade finita. Ou pior do que isso, que a única concepção válida é aquela cunhada pela tradição cristã. Assim, quando, por exemplo, na teoria da livre criação das verdades eternas é afirmado que elas foram criadas pelo mesmo gênero de causalidade pelo qual Deus produziu todas as coisas (Descartes 1, AT I, pp. 151-152), isto é, por meio da causalidade eficiente, alguns intérpretes do cartesianismo se permitem concluir apressadamente que o conceito cartesiano de criação envolve necessariamente a contingência ou finitude das realidades consideradas imutáveis e necessárias. Pois, levando-se em conta a simplicidade divina, sustentar que as verdades eternas foram criadas equivale a afirmar que foram produzidas pela vontade divina, a qual institui necessariamente o contingente, conforme ensinou a tradição medieval. Admitindo não ser possível outra concepção do conceito de criação, conclui-se que Descartes reduz as realidades eternas e necessárias à realidade contingente e finita.

Entretanto, há fortes indícios de que a concepção cartesiana de criação diverge daquela transmitida pela ortodoxia medieval. Observemos a seguinte passagem, encontrada nas Quartas Respostas:

"quando se pergunta se alguma coisa pode se dar o ser a si mesma, quer-se saber apenas se a natureza ou essência de alguma coisa pode ser tal que não tenha necessidade de causa eficiente para ser ou existir"'(Descartes 1, AT IX, p. 186).

A citação acima aproxima ao mesmo tempo em que distancia
Descartes dos filósofos medievais cristãos. A proximidade se dá na concordância em que a criação é uma produção de seres mediante causalidade eficiente, isto é, por meio da vontade. Eles, porém, se distanciam ao descreverem o produto dessa causalidade: a maioria dos medievais afirmava que a vontade divina (causa eficiente) é responsável pela produção exclusiva das coisas existentes, da criação, ao passo que para Descartes a mesma causalidade produz tanto as coisas existentes quanto as realidades eternas e necessárias. A ação criadora em Descartes é total e universal ${ }^{5}$.

Segundo a passagem das Quartas Respostas que acabamos de citar, somente Deus possui uma natureza tal que dispensa uma causa eficiente anterior para ser ou existir. $\mathrm{O}$ critério pelo qual se distingue o criado e o incriado se encontra justamente na necessidade da causalidade eficiente para sua produção, ou seja, tudo o que puder dar o ser ou a existência a si mesmo pode ser considerado incriado, caso contrário é criatura. Ora, a passagem supracitada coloca-nos ante um grave problema, pois se afirmarmos que haveria algo cuja natureza pudesse dar a si o seu próprio ser e sua própria existência, estaremos imediatamente inferindo a existência de algo outro eterno e independente de Deus. Algo absurdo, pois nos levaria a tomá-lo como mais perfeito do que o próprio Deus, em razão da sua independência do ser divino. Descartes, portanto, propõe que todas as coisas, exceto Deus, necessitam de uma causalidade eficiente para ser ou existir. Isso nos permite por ora inferir que o conceito cartesiano de criação envolve tanto as realidades finitas quanto as necessárias e eternas, mas não que estas permaneçam eternas e necessárias em virtude de lhes ser aplicado o conceito de criação. A certeza da necessidade e eternidade dessas realidades produzidas pela ação criadora de Deus provém da análise do conceito de onipotência divina. 


\section{A onipotência divina}

Quando se trata de analisar o conceito de onipotência em Descartes, não se acha entre os autores unanimidade. Há quem defenda que a onipotência significa - devido às teses da simplicidade divina e da indiferença-o poder de instituir o que é contraditório. Para os partidários do possibilismo, o raciocínio é o seguinte: se Deus é onipotente e indiferente, então tudo é contingente. Defendem eles que tendo sido todas as coisas criadas por meio da vontade divina, cuja onipotência é capaz de tornar verdadeiro o que repugna à razão, nada mais é necessário. Esses autores acreditam que o conceito cartesiano de criação é idêntico ao conceito criado e lapidado pelos medievais.

Por outro lado, os textos cartesianos onde a onipotência divina adquire altíssima relevância nos garantem que um Deus absolutamente simples, indiferente e onipotente pode criar as coisas eternas, necessárias ou imutáveis sem que sua criação envolva qualquer resquício de contingência. Com efeito, entender que as realidades eternas, necessárias ou imutáveis dispensam diretamente a vontade divina equivale a compreender que essa vontade não pode criar tais realidades sem maculá-las com o caráter da contingência. Criar o imutável é a mais excelente prova da onipotência, conforme atestam as Quintas Respostas:

"Quanto ao que vós dizeis que 'vos parece difícil ver estabelecida alguma coisa de imutável e eterna outra que Deus', teríeis razão se se tratasse de uma coisa existente, ou somente se eu estabelecesse alguma coisa de tal modo imutável que sua imutabilidade mesma não dependesse de Deus [...] Mas penso que, porque Deus assim o quis e assim as dispôs, elas são imutáveis e eternas" (Descartes 1, AT VII, p. 380).
A tese da onipotência divina em Descartes representa o fim das concepções referentes a "realidades incriadas", porque para ser ou existir tudo depende de Deus, ut efficiens \& totalis causa.

Além desta passagem - que não é, aliás, a única onde Descartes afirma a necessidade da causalidade eficiente na instituição das realidades outrora consideradas incriadas - existe outra na qual explicitamente se afirma que a onipotência divina exige a imutabilidade das realidades eternas e necessárias:

"dirão que, se Deus estabeleceu estas verdades, ele as poderia mudar como um rei às suas leis; a que é preciso responder que sim, se sua vontade pode mudar. - Mas eu as compreendo como eternas e imutáveis. - E eu julgo o mesmo de Deus. - Mas sua vontade é livre. - Sim, mas seu poder é incompreensível” (Descartes 1, AT I, pp. 145-146).

Como se sabe, a imutabilidade da vontade divina não é algo cartesiano. Descartes, por sua vez, a evoca como demonstração de que nela é que se fundamenta a imutabilidade das realidades necessárias. Com efeito, Deus, cuja vontade é imutável e onipotente, pode seguramente estabelecer, por meio dela, tudo o que há de imutável e necessário, mesmo que sua vontade seja considerada absolutamente livre. Ante a iminente objeção segundo a qual de uma vontade livre, mesmo concebida como imutável, não pode provir diretamente algo necessário, Descartes introduz o conceito de incompreensibilidade divina.

\section{A incompreensibilidade divina}

Eis o que devemos entender por incompreensibilidade divina: 
"Sei que Deus é o autor de todas as coisas. Eu digo que sei, e não que o concebo nem que o compreendo; pois se pode saber que Deus é infinito e onipotente, embora nossa alma finita não possa compreendê-lo nem concebê-lo [...] pois compreender é abarcar pelo pensamento, mas para saber uma coisa, é suficiente tocá-la pelo pensamento" (Descartes 1, AT I, p. 152)

A carta de agosto de 1641 esclarece:

"Pois como digo freqüentemente, na questão que diz respeito a Deus, ou ao infinito, não é preciso considerar o que dele podemos compreender (porque sabemos que não deve ser compreendido por nós), mas somente o que dele podemos conceber, ou entender por qualquer razão certa" (Descartes 1, AT III, p.430).

Inicialmente a incompreensibilidade é vista como um atributo divino decorrente de seu ser infinito. Tal incompreensibilidade se impõe à natureza humana, que, sendo finita, não pode compreender o infinito, pois "é da natureza do infinito que minha natureza, que é finita e limitada, não possa compreendê-lo" (Descartes 1, AT IX, 37).

Entretanto, embora Deus seja incompreensível à natureza humana, Descartes assegura que é possível saber algo acerca dele, por exemplo, que é incompreensível, criador das essências e das existências, perfeito, infinito, soberanamente bom, etc., e que, se por um lado devemos evitar tentar compreendê-lo, por outro nos é possível conceber ou entender algo acerca dele, isto é, podemos tocar com o pensamento esta realidade incompreensível. Tocar com o pensamento significa precisamente saber de modo certo, validando, portanto, a razão. Sabendo qual é o significado da incompreensibilidade, tomemo-la no contexto da indiferença divina.
É perfeitamente aceitável e compreensível que uma vontade livre produza atos contingentes, mesmo em se tratando da vontade divina, que é considerada imutável, devido à analogia estabelecida entre a vontade divina e a humana. Nisto insistiu toda a tradição medieval cristã.

Descartes, porém, não admite uma concepção analógica de ambas as vontades, o que pôde ser claramente percebido quando da investigação sobre o tema da indiferença. A vontade divina representa uma negação radical do livre-arbítrio, por causa da indiferença, posto não the ser possível escolher entre alternativas nem agir determinada por qualquer espécie de consideração lógica, física, metafísica e moral. Donde resulta que a compreensão de nossa vontade não nos autoriza estabelecer qualquer analogia com a vontade divina, pois esta é incompreensível para uma razão finita. Uma vez que a vontade divina não é como a humana, torna-se impossível de fato ao intelecto finito compreender como ela cria realidades eternas, necessárias e imutáveis sem lhes prejudicar minimamente a necessidade, e ao mesmo tempo garante a eficácia da razão humana:

"Deus é uma causa cuja potência ultrapassa os limites do entendimento humano, e a necessidade das verdades não excede o nosso conhecimento, elas [verdades eternas] são alguma coisa de inferior e sujeita a esta potência incompreensível" (Descartes 1, AT I, 150).

Para uma interpretação irracionalista de Descartes a incompreensibilidade divina representa definitivamente a anulação da razão humana. Segundo a citação acima, porém, o necessário, instituído por um Deus cuja potência ultrapassa o nosso entendimento, não excede o nosso intelecto, ou seja, Ele os criou adequados um ao outro. Atentos, pois, ao seu significado mais profundo, podemos ver claramente que a tese da incompreensibilidade indica ser impossível para o intelecto finito 
compreender como a vontade divina, absolutamente livre e indiferente, institui enquanto causa eficiente, ou seja, por criação, as realidades necessárias ou a própria necessidade sem qualquer prejuízo à sua imutabilidade, e sem diminuir ou invalidar o poder da razão.

\section{Conclusão}

Portanto, os argumentos utilizados pelos partidários de um suposto irracionalismo cartesiano pressupõem equivocadamente uma identidade entre o conceito cartesiano de criação e aquele cunhado pela filosofia cristã. Daí considerarem a indiferença divina uma pedra de tropeço para Descartes.

Apoiados, porém, em relevantes passagens da obra cartesiana, mostramos que seu autor entende criação de modo diferente do da tradição e que, levando-se em consideração os conceitos de onipotência e incompreensibilidade, não apenas é descartado o irracionalismo, mas se confere à razão toda a eficácia necessária, porquanto tudo o que ela conhece depende necessariamente da ação divina, totalmente simples e pura. Tudo indica que Descartes leva a garantia divina a um grau absoluto ao defender a necessária dependência de todas as coisas do Deus "soberano, eterno, infinito, imutável, onisciente, onipotente e criador universal de todas as coisas que estão fora dele" (Descartes 1, AT IX, p. 32).

\section{REFERÊNCIAS BIBLIOGRÁFICAS:}

\section{Obras de Descartes:}

1. OEUVRES DE DESCARTES. Ed. de C. Adam e P. Tannery. XI vols. Paris: Vrin, 1996.

2.Tutte le Lettere, 1619-1650. Testo francese, latino e olandese. Org. de Giulia Belgioioso. Milão: Bompiani, 2005.

\section{Demais obras:}

3.BEYSSADE, J-M. Descartes au fil de l'Ordre. Paris: Puf, 2001.

4. CURLEY. E. M. Descartes on the Creation of the Eternal Truths. In The Philosophical Review, vol. XCIII, n. 4. October. New York: 1984.

5. FRANKFURT, H. Descartes on the Creation of the Eternal Truths. In The Philosophical Review, vol. LXXXVI, n 1. January. New York: 1977.

6. GHISALBERTI, A. Guilherme de Ockham. Tradução de Luís A. De Boni. Porto Alegre: EDIPUCRS, 1997.

\section{The Descartes's rationalism called into question}

Abstract: Due to the resumption of the theory of the creation of the eternal truths, some interpreters bring to the contemporary international debate a interesting bias interpretative of Descartes' thought. According to them, when Descartes presents the indifference of the will as an attribute of God, he introduces a concept totally dangerous, from which derives the incompatibility between the Cartesian system and divine indifference, deflagrating, finally, a radical irrationalism.

Keywords: Descartes. Freedom. Divine Indiference. Racionalism. Irracionalism.

\section{NOTAS:}

1. Para a ortodoxia escolástica, Deus podia escolher e, de fato escolhia entre as várias alternativas possíveis encontradas em seu intelecto. Aquelas escolhidas eram atualizadas, ganhando existência efetiva. A indiferença divina, por sua vez, implica que nada precede a ação pela qual Deus institui todas as coisas, ou seja, nenhuma ideia exemplar, nenhum arquétipo, nenhuma essência possível. Como nada precede a ação 
divina, nenhuma escolha é feita por Deus. Por conseguinte, a indiferença da vontade divina exclui o livre-arbítrio.

2. A posição cartesiana acerca da vontade divina pode ser compreendida graças à supressão desde Ockham dos arquétipos no entendimento divino, conforme os quais seriam criados os existentes. Tal supressão veio a significar o fim da distinção ou hierarquia entre as faculdades divinas, surgindo, por conta disso, a tese da unidade absoluta entre essas faculdades. A Ockham coube pôr um fim definitivo à questão dos arquétipos, reduzindo-os a entes de razão, não podendo gozar jamais de existência extramental. Existem apenas as substâncias singulares e criadas imediatamente pela onipotência divina. Deus as conhece enquanto singulares. A realidade existencial do singular consiste na existência exterior ao pensamento; coisas como universais, gêneros e espécies, ideias, essências são reduzidas a nomes. No intelecto humano, elas existem como conhecimento abstraído de nossa experiência dos particulares. Desaparecendo as ideias do intelecto divino e os universais nas coisas, desaparece igualmente a precedência do intelecto à vontade. Ora, se se pensava na conformidade da vontade ao intelecto, porque neste residiriam as essências exemplares segundo as quais somente as coisas existentes seriam criadas, agora, com o fim das ideias arquetípicas e concebida somente a existência real dos indivíduos, Ockham abre um universo em que nenhuma necessidade inteligível se interpõe, mesmo em Deus, entre sua essência e suas obras. (Ver Alessandro Ghisalberti, 6 , capítulos III e VII).

3. Cabe ressaltar que depender de Deus é o mesmo que ter sido criado por ele. Essa é uma observação importante, pois a noção tradicional de criação envolve necessariamente a contingência, finitude ou cessação da coisa criada. Uma vez que Descartes coloca o necessário como dependente de Deus, pode-se inferir que tudo é contingente. Consequentemente, a razão, enquanto conhecedora do necessário, fica em uma situação um tanto desagradável.

4. Por Exemplo, Curley e Beyssade. Não desenvolveremos a solução apresentada por esses célebres autores, mas cuidaremos de apresentar uma alternativa à solução do problema, tendo como núcleo o conceito cartesiano de criação.

5. "Vós me perguntais in quo genere causae Deus disposuit aeternas veritatis [em que gênero de causa Deus dispôs as verdades eternas]? Eu vos respondo que in eodem genere causae [pelo mesmo gênero de causalidade] que ele criou todas as coisas, ou seja, ut efficiens \& totalis causa [como causa eficiente e total]" (Descartes 1, AT I, pp. 151-152).

6. Ver também a carta a Clerselier (Descartes 1, AT IX, pp. 210-211).
ESPINOSA: UM PENSAMENTO DA ATUALIDADE E DA CRÍTICA À UTOPIA POLÍTICA

Daniel Santos da Silva

Resumo: Este artigo tenta localizar alguns pontos nos quais pode se embasar a crítica de Espinosa à filosofia política utópica, esta muitas vezes baseada em uma noção transcendente de poder. Fazemos isso dando relevo a algumas noções, como a de experiência e a de indivíduo, além de focalizarmos a importância da noção de conatus no estabelecimento de uma ontologia da atualidade da natureza humana, na qual, do ponto de vista cognitivo, conhecimento imaginativo e racional afirmam ambos a atualidade dessa natureza humana e permitem a proposição de regimes políticos baseados em tal atualidade.

Palavras-chaves: Política, experiência, utopia, indivíduo, conatus.

Nos parágrafos iniciais do Tratado Politico, Espinosa demarca o terreno de sua investigação em pelo menos dois pontos: 1) um metodológico, que assim chamamos baseados em sua crítica ao modo como fizeram ou tentaram fazer política os filósofos até sua época além da diretiva do quarto parágrafo que traça um paralelo epistêmico entre as paixões humanas e os fenômenos físicos da atmosfera; 2)um ontológico, que assim chamamos tendo em vista os alicerces da passibilidade humana, ou seja, a condição do homem de pars natura - fator este sustentado mais especificamente na Ética. Na chave que usamos para essa investigação, percebemos como a primeira demarcação está envolvida na segunda e vice-versa, num movimento de mútua determinação. Em outras palavras, a política se constitui por homens atravessados por paixões - afetos que

* Doutorando do Departamento de Filosofia da USP. 